\title{
A Three Dimensional Numerical Simulation of Double-U Pile Heat Exchangers
}

\author{
Zhonghao Wang Pingfang Hu Lu Xing Na Zhu Fei Lei
}

\begin{abstract}
The Ground Source Heat Pump system with pile heat exchangers has been used in engineering in recent years. In this paper, a three-dimensional numerical model of double-U pile heat exchangers is established which was verified through the comparison with ground thermal response test results. The influencing factors for the heat exchange performance of double-U pile heat exchangers are analyzed including pile depth, inlet temperature, initial ground temperature and ground thermal conductivity. An improved method is proposed on the basis of the cylindrical source model, combining with the numerical model. The improved method which is simpler than general analytical model can be used to obtain the ground thermal properties and thermal resistance of energy pile.
\end{abstract}

\section{NTRODUCTION}

Nowadays, ground source heat pump technology is the most effective way in the utilization of shallow geothermal energy, and it has been widely used in the world. The ground source heat pump system with pile heat exchangers has become the research hot spot as it has advantages in making full use of land area, reducing the initial investment and enhancing heat transfer performance of the heat exchangers.

The transient heat transfer period in energy pile is much longer than that in vertical borehole because the diameter of the pile is much larger and the depth is shorter than those of vertical borehole. Thus the error would be large if the conventional model is still used which assumes the heat transfer process in the borehole is a steady one (Hu, et al. 2014). Recently, some methods have been developed to study the thermal performance of pile heat exchangers. Zarrella and Carli (2013) and Zarrella, et al (2013) introduced the CaRM numerical model for spiral coil and $U$ type pile heat exchangers and compared the thermal performance between them. Furthermore, Park, et al (2013) developed a numerical model for pile heat exchangers with ABAQUS software, and validated its reliability with a thermal response test. Li and Lai (2012) analyzed and compared the spiral-line model and the cylindrical-surface model, and found that both model can be used to describe the heat transfer of energy piles.

In this paper, a three-dimensional numerical model of pile heat exchangers is established based on COMSOL Multiphysics. This model can accurately analyze the heat conduction between the pile and the soil, and the coupled heat transfer of the pipe wall. It is verified in comparison with result of ground thermal response test. The numerical model of double- $\mathrm{U}$ pile heat exchangers is established, and the influencing factors for the heat exchange performance of double- $U$ pile ground heat exchangers are analyzed based on the model. An improved method is proposed on the basis of the cylindrical source model, combining with the numerical model. The inversion result was compared with that of line source model and composite cylindrical source model.

Pingfang Hu (pingfanghu21@163.com) is a professor in building energy engineering and Zhonghao Wang is a graduate student at Huazhong University of Science and Technology. 


\section{ANALYTI CAL MODEL}

As the soil acts as the heat source of the GSHP systems, it is necessary to obtain its thermophysical parameters in the design process. The parameters have significant effect on calculation of number and depth of boreholes, and the initial investment of the systems. Studies show that about $10 \%$ error of thermal conductivity will cause $4.5 \% \sim 5.8 \%$ error of pile heat exchanger length (Kavanaugh 1998). At the same time, the error of the thermal properties can also lead to the unbalance of the designed load and the actual load, which will then affect the operational performance of the systems. Therefore, the rational heat transfer model needs to be selected to accurately calculate the thermal physical parameters of the soil.

\section{Infinite line source model and cylindrical source model}

The heat transfer model for heat exchanger can be divided into the internal and the external heat transfer model. As for the common borehole heat exchangers, the geometry size and heat capacity inside the borehole are quite small, and generally the temperature can achieve a relatively stable stage in several hours. Thus, the heat exchange inside the borehole can be approximately considered as steady heat transfer process. The arithmetic average of the inlet and outlet fluid temperature can be regarded as average temperature of circulating fluid in pipe for both temperature results are close for regular operating conditions.

The internal heat transfer model mainly includes one-dimensional, two-dimensional and quasi three dimensional models. One-dimensional model ignores the influence of the pipe spacing and some other factors, and the calculating error may be large. And the calculating process of the quasi three dimensional heat transfer model is more complex compared with other two models. Thus, the two-dimensional heat transfer model is commonly used in practical engineering (Loveridge and Powrie 2014).

The two-dimensional model neglects the heat transfer in the axial direction, and analyzes the effect of the geometric configuration on the cross section. The thermal resistance between the fluid and the borehole wall can be obtained through the model. The borehole thermal resistance for vertical double $U$ type heat exchangers can be obtained through equation (1) (Hellstrom 1991).

$$
R_{b}=\frac{1}{4}\left\{\frac{1}{2 \pi \lambda_{g}}\left[\ln \left(\frac{d_{b}^{4}}{4 d_{o} d^{3}}\right)+\frac{\lambda_{g}-\lambda_{s}}{\lambda_{g}+\lambda_{s}} \cdot \ln \left(\frac{d_{b}^{8}}{d_{b}^{8}-d^{8}}\right)\right]+\frac{1}{2 \pi \lambda_{p}} \cdot \ln \left(\frac{d_{o}}{d_{i}}\right)+\frac{1}{\pi d_{i} h}\right\}
$$

As for the external heat transfer process, the infinite line source model and cylindrical source model are commonly used, and the average fluid temperature can be expressed in equation (2) and equation (3) (Ingersoll and Plass 1948).

$$
\begin{gathered}
T_{f}=T_{0}+q_{l} \cdot\left[R_{b}+\frac{1}{4 \pi \lambda_{s}} \cdot E\left(\frac{d_{b}^{2} \rho_{s} c_{s}}{16 \lambda_{s} \tau}\right)\right] \\
T_{f}=T_{0}+q_{l}\left[\frac{G(F O, 1)}{\lambda_{s}}+R_{b}\right]
\end{gathered}
$$

where $\quad F_{O}=\frac{4 \lambda_{s} \tau}{\rho_{s} c_{s} d_{b}^{2}}$

\section{Composite cylindrical source model}

Due to the particularity of pile heat exchangers, such as the large heat capacity of pile foundation, more time will be required to reach the steady state compared with the common vertical borehole heat exchangers. If the heat 
transfer inside the borehole is treated as steady heat exchange process, the error would be large. The large pile diameter and the small depth limit the utilization of composite line source model. A composite cylindrical source model was established based on the composite line source model and the cylindrical source model (Hu, et al. 2014).

According to the composite cylindrical source model, the borehole thermal resistance varies with time, and it can be expressed with $\mathrm{G}$ function and Fourier number (Hu, et al. 2014).

$$
R_{b}(\tau)=\frac{G\left(F o^{\prime}, 1\right)}{\lambda_{g}}-\frac{G\left(F o^{\prime \prime}, 1\right)}{\lambda_{g}}
$$

where $F_{O}{ }^{\prime}=\frac{a^{\prime} \tau}{r_{w}{ }^{2}}=\frac{\lambda_{g} \tau}{r_{w}^{2} \rho_{g} c_{g}} F^{\prime} O^{\prime}=\frac{a^{\prime} \tau}{r_{b}^{2}}=\frac{\lambda_{g} \tau}{r_{b}^{2} \rho_{g} c_{g}}$.

Then the average fluid temperature can be expressed in the equation (5):

$$
T_{f}(\tau)=T_{0}+q_{l}\left(\frac{G(F o, 1)}{\lambda_{s}}+\frac{G\left(F o^{\prime}, 1\right)}{\lambda_{\mathrm{g}}}-\frac{G\left(F o^{\prime \prime}, 1\right)}{\lambda_{\mathrm{g}}}\right)
$$

The model can be used in analysis of performance and TRT for energy pile.

\section{EXPERI MENTAL TEST}

An experimental test is conducted in Wuhan, China. As the underground water level is relatively low, there will be no obvious groundwater flow in the process, and then the influence of groundwater seepage can be ignored. The length of tested pile is $45 \mathrm{~m}$, and its diameter is $600 \mathrm{~mm}$. The double U HDPE pipe is used in the test, and its outer diameter and inner diameter is $25 \mathrm{~mm}$ and $20 \mathrm{~mm}$ respectively. The heat exchanger is in the pile (see Fig.1). The thermal conductivity of pipe wall is $0.51 \mathrm{~W} /(\mathrm{m} \cdot \mathrm{K})$. The backfill material is cement concrete. The average initial temperature of the soil is $19.8{ }^{\circ} \mathrm{C}$, the average flow rate of circulating water is $1.3 \mathrm{~m}^{3} / \mathrm{h}$. The test is performed for about $48 \mathrm{~h}$ with $3.5 \mathrm{~kW}$ heating power. The temperatures are measured at 1 -min intervals. At first the heat transfer between the fluid and the soil is not sufficient so the inlet and outlet fluid temperature difference is relatively small. After an initial transient process the heat transfer is close to stable state then the temperature difference tends to be nearly constant (see Fig.2).

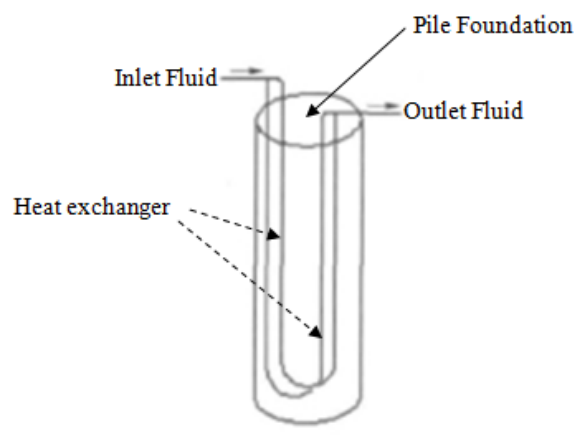

Figure 1 Double-U heat exchanger in a pile.

\section{NUMERI CAL MODEL}

The three dimensional numerical model for pile heat exchangers is established based on COMSOL Multiphysics which combines the Finite Element Method (FEM) and the Computational Fluid Dynamics (CFD). The heat conduction between the pile and the soil, and the coupled heat transfer of the pipe wall can be analyzed accurately by this numerical model (Go, et al. 2014). 


\section{The parameter setting}

As the model is built based on experimental test, parameter settings should be in accordance with the test condition. Pile depth is $45 \mathrm{~m}$. Pile diameter, outer and inner diameter of the pipe are $0.6,0.025$ and $0.020 \mathrm{~m}$ respectively. Table 1 shows the thermal physical parameters of the soil, backfill material and the pipe. The calculation of thermal physical properties of the soil is based on the composite cylindrical source model which has been verified (Hu, et al. 2014). The backfill material is cement concrete, and the initial soil temperature is $19.8{ }^{\circ} \mathrm{C}$.

Table 1. Thermal physical parameters

\begin{tabular}{cccc}
\hline & Thermal Conductivity $(\mathbf{W} /(\mathbf{m} \cdot \mathbf{K})$ & $\begin{array}{c}\text { Specific heat capacity } \\
(\mathrm{J} /(\mathrm{kg} \cdot \mathbf{K}))\end{array}$ & $\begin{array}{c}\text { Density } \\
\left(\mathrm{kg} / \mathbf{m}^{3}\right)\end{array}$ \\
\hline \hline Soil & 2.17 & 952.4 & 2100 \\
Cement concrete & 2.5 & 814.8 & 2700 \\
HDPE & 0.51 & $/$ & $/$ \\
\hline
\end{tabular}

The inlet fluid temperature is the same as that in the experimental test, and it is defined as the global variable $\left(T_{\text {in }}\right)$ which is imported into the model. The average fluid flow rate is $1.3 \mathrm{~m}^{3} / \mathrm{h}$.

The free tetrahedron mesh is adopted in the model. The three different kinds of meshing number are selected, and the temperature variation of outlet fluid was compared. According to the error of three meshing density, meshing density (25681) was adopted for the model.

\section{Validation of the numerical model}

The model can be validated through the comparison of the outlet fluid temperature between numerical simulating results and the measured values. Figure 2 shows the comparison of the outlet fluid temperature for 48 hours. It is obviously shown that the numerical simulating results and the measured values are in good agreement, especially after the outlet fluid temperature reaches the balance. The deviation at the short term may be mainly resulted from the power fluctuation. In the test, the heating power fluctuates sometimes due to the power supply situation on site. The maximum relative error occurs in the initial stage, and it is limited within 3\% after 10 hours' operation. Therefore, it's proven that the three-dimensional numerical model is reliable.

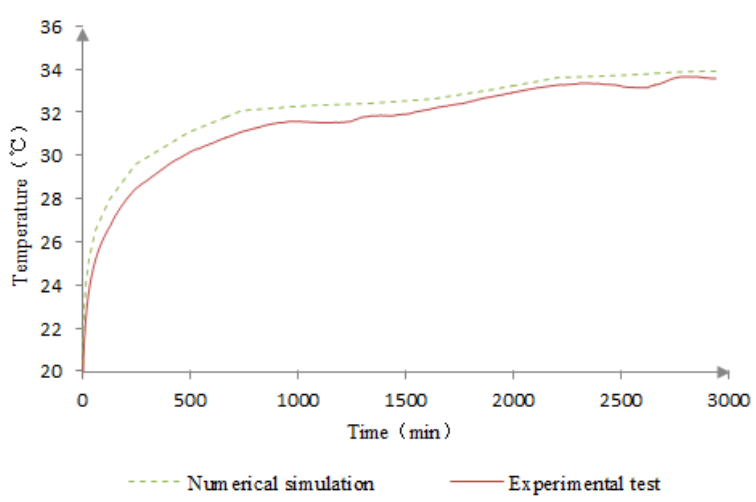

Figure 2 Outlet fluid temperature.

\section{AFFECTI NG FACTORS FOR PERFORMANCE OF PI LE HEAT EXCHANGERS}


The heat exchange performance of pile heat exchangers is related to the depth of pile and some other factors. The three dimensional numerical model can be used for analyzing the effect of various factors on heat transfer performance. It can provide reference for the design and operation of pile heat exchangers.

The software COMSOL is used to establish the double $U$ type heat exchange model, The simulating time is set as $3000 \mathrm{~min}$. Pile diameter, outer and inner diameter of the pipe are $0.6 \mathrm{~m}, 0.025 \mathrm{~m}$ and $0.020 \mathrm{~m}$ respectively. The thermal physical parameters of the surrounding soil, the backfill material and the buried pipe are as shown in Table 2. The operation mode is cooling.

Table 2. Thermal physical parameters

\begin{tabular}{c||c}
\hline \multicolumn{1}{c||}{ Soil } & $\begin{array}{c}\text { Thermal conductivity: } 2.5 \mathrm{~W} /(\mathrm{m} \cdot \mathrm{K}) \\
\text { Specific heat capacity: } 1200 \mathrm{~J} /(\mathrm{kg} \cdot \mathrm{K}) \\
\text { Density:2000 } \mathrm{kg} / \mathrm{m}^{3}\end{array}$ \\
\hline \hline \multirow{2}{*}{ Backfill material } & $\begin{array}{c}\text { Thermal conductivity:2.0 W/ } /(\mathrm{m} \cdot \mathrm{K}) \\
\text { Specific heat capacity: } 850 \mathrm{~J} /(\mathrm{kg} \cdot \mathrm{K}) \\
\text { Density: } 2800 \mathrm{~kg} / \mathrm{m}^{3}\end{array}$ \\
\hline \hline Pipe & Thermal conductivity:0.49 W/(m・K) \\
\hline
\end{tabular}

\section{Pile depth}

According to Figure 3, the heat exchange rate per unit length decreases while the pile depth increases. Although the longer pile has bigger exchanging area and the total exchange rate as well, the outlet fluid temperature is reduced which leads to the enhancement of thermal effect between inlet fluid and outlet fluid.

\section{Soil thermal conductivity}

As shown in Figure 4, the heat exchange rate per unit length increases as the soil thermal conductivity increases. And the maximum variation ratio of the heat exchange rate can reach about $10 \%$.

\section{Inlet fluid temperature}

As shown in Figure 5, the heat exchange rate per unit length increases as the inlet fluid temperature increases, and their relationship tends to be linear. When the pile depth takes $35 \mathrm{~m}$, the linear relationship can be expresses as the following equation: $\mathrm{q} 1=3.7 \mathrm{Tin}-72.7$. Thus, if the inlet fluid temperature rises by $1^{\circ} \mathrm{C}$, the heat exchange rate per unit length is supposed to increase about $3.7 \mathrm{~W} / \mathrm{m}$.

Increment of the inlet fluid temperature will lead to the larger temperature difference between the fluid and the soil, the heat exchange rate per unit length will also be increased. However, increasing the inlet fluid temperature will reduce the efficiency of the heat pump.

\section{Initial soil temperature}

As shown in Figure 6, the heat exchange rate per unit length decreases linearly as the initial soil temperature increases. When the initial soil temperature rises by $1{ }^{\circ} \mathrm{C}$, the heat exchange rate per unit length will decrease in the range from $3.5 \mathrm{~W} / \mathrm{m}$ to $4.5 \mathrm{~W} / \mathrm{m}$.
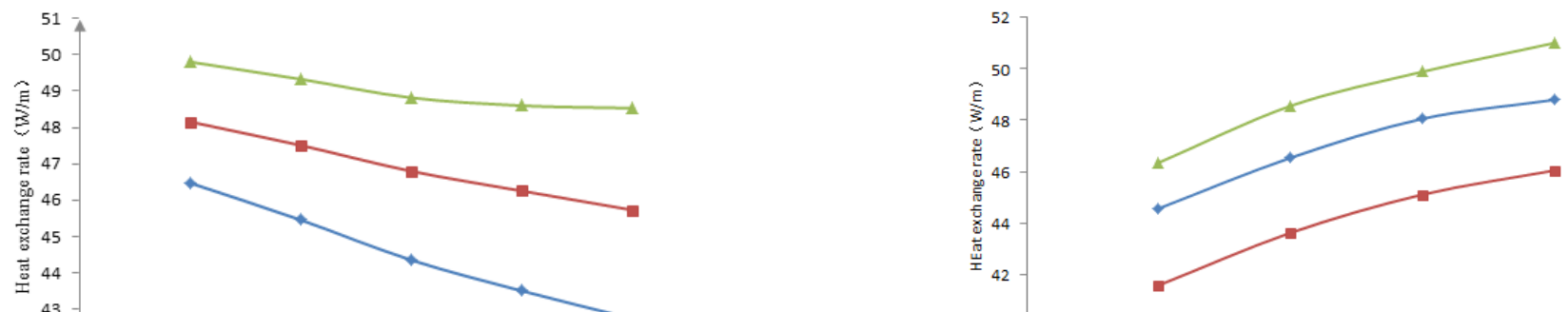
Figure 3 Heat exchange rage variation versus pile depth.

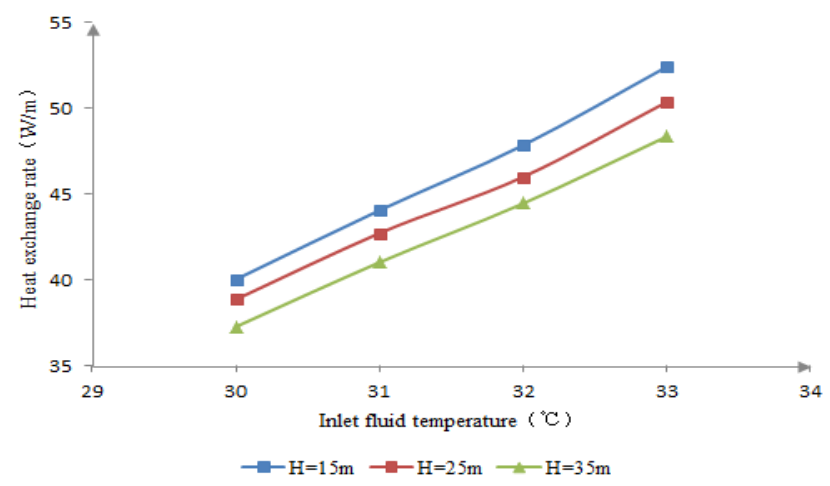

Figure 5 Heat exchange rage variation versus inlet fluid temperature.
Figure 4 Heat exchange rage variation versus soil thermal conductivity .

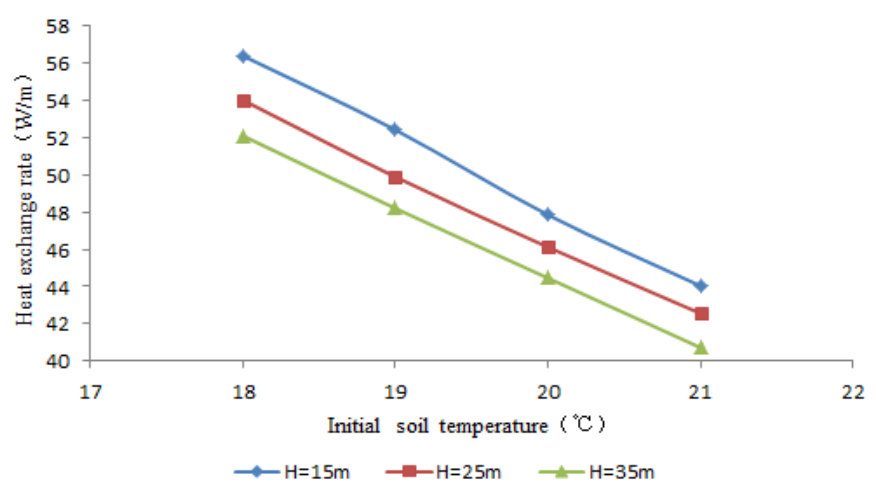

Figure 6 Heat exchange rage variation versus initial soil temperature.

\section{MPROVED METHOD}

Here we proposed an improved method to obtain the thermal property of soil and thermal resistance of energy pile. The numerical model established in this paper can not only simulate the inlet and outlet fluid temperature, but also the average temperature of the borehole wall at real time, and then the borehole thermal resistance $\mathrm{R}_{\mathrm{b}}\left({ }^{\tau}\right)$ under unsteady state can be obtained through the following two equations.

The heat exchange rate per unit length and the borehole thermal resistance can be expressed in the equation (6) and equation (7), respectively.

$$
\begin{aligned}
& q_{l}=\frac{c m\left(T_{\text {in }}-T_{\text {out }}\right)}{H} \\
& R_{b}(\tau)=\frac{T_{f}-T_{b}}{q_{l}}
\end{aligned}
$$

Then the equation (3) is used to obtain the thermal properties of soil. Equation (3), (6) and (7) constitute the main content of an improved method. The borehole thermal resistance could be obtained by a simple equation (7) instead of a complicated calculation in general analytical method, and the borehole wall temperature $\mathrm{T}_{\mathrm{b}}$ is obtained by numerical simulation. Then the soil thermal conductivity can be inversed by equation (3).

Generally the temperature sensors are installed at the inlet and outlet of the pipe for experimental test, and it is definitely not feasible to install the sensors widely to cover the borehole wall in the practical engineering, so the field test can't provide accurate average temperature of the borehole wall which exposes its disadvantage compared with 
numerical simulation. While solving the thermal properties of soil, the analytical model should be adopted with complicated calculations obtaining the borehole thermal resistance, like the equation (1) or equation (4).

Compared with other analytical model in previous sections, the improved method based on the cylindrical model and numerical model can be used to obtain the borehole thermal resistance easily under unsteady state. The method is also applicable for many other types of heat exchangers, including spiral heat exchangers.

According to the above formulas of different models, the line source model, composite cylindrical source model and the improved method are established respectively on the MATLAB platform. These three models are analyzed and compared based on the existing experimental test data. Among all the models, the improved method is only used to invert the thermal conductivity of soil. The results are shown in Table 3.

According to Table 3, the result of line source model is quite different from that of the composite cylindrical source model. The main reason is that the former one linearize the heat transfer between the pile and the soil which may result in a major error, and the internal heat transfer can't be handled as a steady-state progress. The inversion result of improved method is close to that of composite cylindrical source model. Thus, the improved method can be adopted for the designing of GSHP systems with pile heat exchangers, and its accuracy is high with a relative difference of about $4.6 \%$ compared with the result of composite cylindrical source model.

Table 3 Calculated results for different models

\begin{tabular}{cccc}
\hline Model & Line source model & Composite cylindrical model & Improved method \\
\hline \hline $\begin{array}{c}\text { Thermal conductivity } \\
\mathrm{W} /(\mathrm{m} \bullet \mathrm{K})\end{array}$ & 1.87 & 2.17 & 2.27 \\
\hline
\end{tabular}

Current studies on the pile heat exchanger are mainly based on analytical or dimensional simulation method. This paper developed a method combining a three-dimensional model with analytical model. Thematically speaking, the borehole thermal resistance could be obtained by a simple equation (7) instead of a complicated calculation in general analytical method, and the borehole wall temperature $T_{b}$ is obtained by numerical simulation. So the calculation of the borehole thermal resistance is simpler and the method is suitable for wider application compared with current analytical model. That is, the method can be used in the calculation of vertical heat exchanger and spiral heat exchanger.

\section{CONCLUSION}

A three-dimensional numerical model of pile ground heat exchangers is established which can accurately analyze the heat conduction between the pile and the soil, and the coupled heat transfer of the pipe wall. The model is utilized to study the relationship between heat exchange performance and affecting factors, including pile depth, inlet temperature, ground initial temperature and ground thermal conductivity.

The improvement of this paper is to present a new method, which combines a three-dimensional numerical model and combined with the cylindrical source model. The calculation of the borehole thermal resistance using this method is simpler than analytical model, and the method is suitable for wider application compared with current analytical model. That is, the method can be used in the calculation of vertical heat exchanger and spiral heat exchanger.

\section{ACKNOWLEDGMENTS}


The authors would like to acknowledge the supports from the National Nature Science Foundation of China ( No.51678262) and the project of Hubei Science and Technology Support Project (No. 2014BAA137). This project was also funded by the Science and Technology Project of Communications Department of Henan Province (No. 2013204) and the Plan of Science and Technology Development of Henan Province (No.142102310239).

\section{NOMENCLATURE}

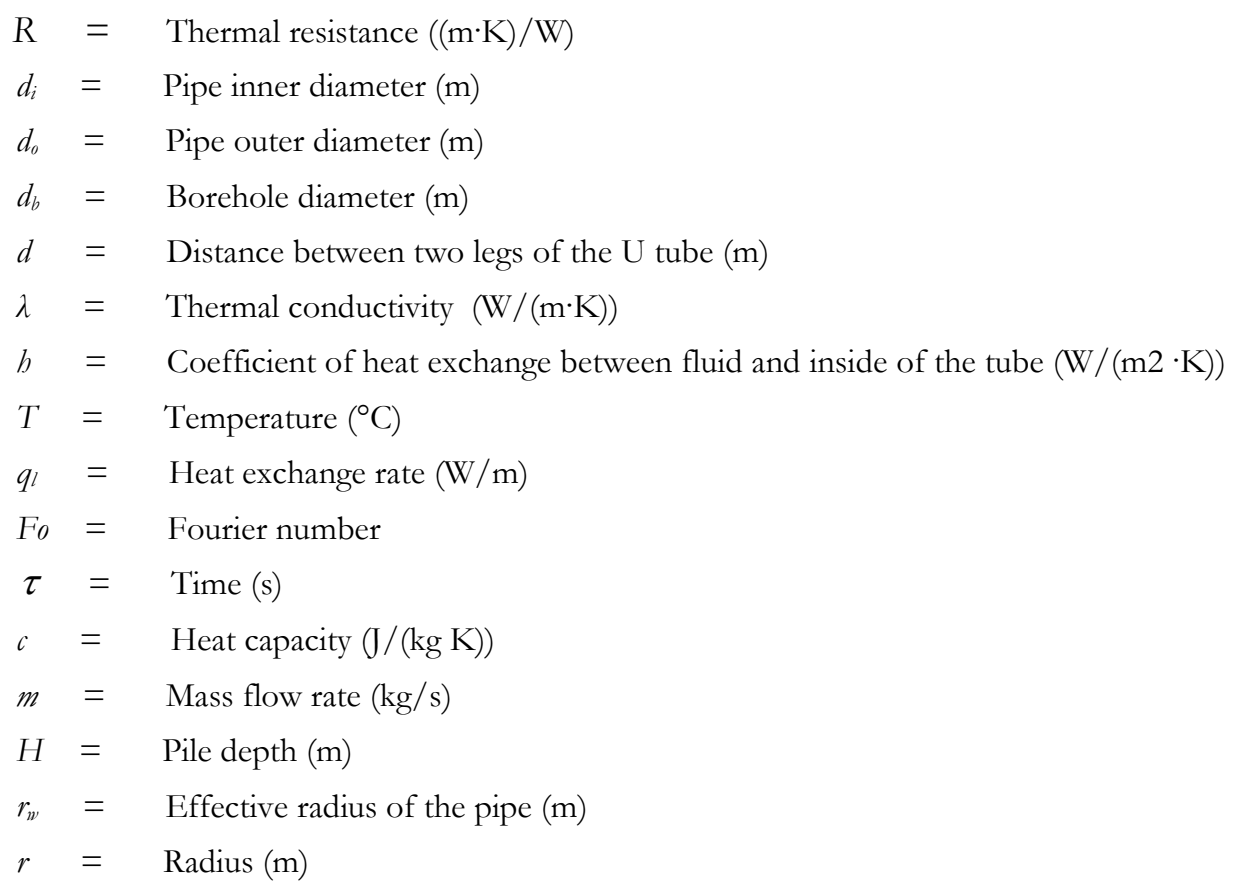

\section{Subscripts}

$\begin{aligned} b & =\text { Borehole } \\ g & =\text { Backfill material } \\ s & =\text { Soil } \\ f & =\text { Fluid } \\ p & =\text { Pipe } \\ \text { in } & =\text { Inlet } \\ \text { out } & =\text { Outlet }\end{aligned}$

\section{REFERENCES}

Go, G.-H., S.-R. Lee and S. Yoon. 2014. Design of spiral coil PHC energy pile considering effective borebole thermal resistance and groundwater advection effects. Applied Energy 125(2): 165-178.

Hellstrom, G. 1991. Ground heat storage: thermal analysis of duct storage systems. Department of Mathematical Physics, University of Lund, Sweden. 
Hu, P. F., J. Zha, F. Lei, N. Zhu and T. W. Wu. 2014. A composite cylindrical model and its application in analysis of thermal response and performance for energy pile. Energy and Building 84(12): 324-332.

Ingersoll, L. R. and H. J. Plass. 1948. Theory of the ground pipe source for the heat pump. Heating, piping \& Conditioning 54(7): 339-348.

Kavanaugh, S. P. 1998. Field tests for ground thermal properties method and impact on ground source heat pump. ASHRAE Transactions 104(2): 347-355.

Loveridge, F. and W. Powrie. 2014. 2D thermal resistance of pile heat exchangers. Geothermics 50(4):122-135.

Li, M and A. C. K. Lai. 2012. Heat-source solutions to beat conduction in anisotropic media with application. Applied Energy 96(8): 451-458.

Park, H., S. Lee and S. Yoon. 2013. Evaluation of thermal response and performance of PHC energy pile: Field experiments and numerical simulation. Applied Energy 103(3): 12-24.

Zarrella, A. and M. D. Carli. 2013. Heat transfer analysis of short helical borehole heat exchangers. Applied Energy 102(2): 1477-1491.

Zarrella, A., M. D. Carli and A. Galgaro. 2013. Thermal performance of two types of energy foundation pile: Helical pipe and triple Utube. Applied Thermal Engineering 61(2): 301-310. 